\title{
IMPLEMENTASI EXTREME PROGRAMMING PADA SISTEM INFORMASI PROGRAM KREATIVITAS MAHASISWA BERBASIS WEB
}

\author{
Silvia Oktaviani ${ }^{1}$, Agus Priyanto ${ }^{2}$, Citra Wiguna ${ }^{3 *}$ \\ 1,3 Program Studi Sistem Informasi, Fakultas Informatika Institut Teknologi Telkom Purwokerto \\ ${ }^{2}$ Program Studi Sistem Informatika, Fakultas Informatika Institut Teknologi Telkom Purwokerto \\ Jl. DI. Panjaitan No. 128 Purwokerto
}

${ }^{1} 17103103 @$ ittelkom-pwt.ac.id

${ }^{2}$ agus_priyanto@ittelkom-pwt.ac.id

${ }^{3}$ citra@ittelkom-pwt.ac.id

\begin{abstract}
Abstrak
Pemanfaatan teknologi informasi membantu dunia pendidikan dalam mengolah data untuk mendukung pengambilan keputusan terhadap permasalahan yang sedang dihadapi. Salah satu upaya untuk meningkatkan kualitas lulusan dalam bidang pendidikan di perguruan tinggi adalah melalui Program Kreativitas Mahasiswa (PKM) yang diselenggarakan oleh Direktorat Jenderal Pendidikan Tinggi. PKM merupakan upaya yang dikembangkan untuk menumbuhkan, mewadahi, dan mewujudkan ide kreatif serta inovatif mahasiswa, hal ini dapat mengantarkan mahasiswa menjadi pribadi yang tahu dan taat aturan, kreatif, inovatif dan obektif kooperatif dalam membangun keragaman intelektual. Sejak awal terselenggarakannya PKM di Institut Teknologi Telkom Purwokerto, proses bisnis belum sepenuhnya didukung oleh teknologi informasi. Pengumpulan berkas dalam bentuk hard copy mengakibatkan adanya penumpukan data, dan segala informasi terkait kebutuhan data belum mempunyai tempat penyimpanan yang efisien jika sewaktu-waktu pengguna membutuhkan data dengan cepat, selain itu juga adanya penyimpanan data dapat membantu pengelola untuk menghindari adanya redundancy data. Hal tersebut tentunya dapat menghambat proses bisnis yang ada baik dari sisi pengelola maupun sisi mahasiswa. Adanya penelitian ini bertujuan untuk merancang sebuah sistem yang terkomputerisasi agar proses bisnis dapat berjalan dan terdokumentasikan dengan baik dan efektif dengan menggunakan metode Extreme Programming (XP). Metode XP melakukan pendekatan secara sistematis dan urut mulai dari level planning, design, coding dan testing. Metode ini memberikan sebuah fleksibilitas kepada user dengan melibatkan user secara langsung. Hasil penelitian berupa rancangan sistem informasi berbasis website yang dapat memudahkan pengguna dalam menjalankan proses bisnis, dengan didukung blackbox testing yang mendapatkan hasil valid/sesuai.
\end{abstract}

Kata kunci : Sistem Informasi, Program Kreativitas Mahasiswa (PKM), Website, Extreme Programming (XP), Blackbox Testing.

\section{Pendahuluan}

Perkembangan teknologi informasi membantu dunia pendidikan dalam mengolah data untuk mendukung pengambilan keputusan terhadap permasalahan yang sedang dihadapi. Adanya pemanfaatan sistem pengolahan dan manajemen informasi yang baik akan berpengaruh dalam peningkatan kinerja yang optimal[1].

Program Kreativitas Mahasiswa (PKM) yang diluncurkan oleh Direktorat Jenderal Pendidikan Tinggi merupakan salah satu bentuk implementasi dari Tridharma Perguruan Tinggi dibawah pengelolaan Direktorat Pembelajaran dan Kemahasiswaan (Belmawa) yang dikembangkan sebagai salah satu upaya untuk menumbuhkan, mewadahi, dan mewujudkan ide kreatif serta inovatif mahasiswa[2][3].

Institut Teknologi Telkom Purwokerto menjadi salah satu perguruan tinggi yang menjalankan PKM dan menjadi salah satu syarat wajib bagi mahasiswa Fakultas Informatika dalam pelaksanaan sidang akhir. Berdasarkan data dari pihak pengelola PKM selama 5 tahun terakhir jumlah pendaftar banyak mengalami perubahan. Hal ini dapat dilihat dari jumlah peserta yang mendaftar pada tahun 2016 total yang mendaftar sebanyak 145 tim, tahun 2017 total yang mendaftar sebanyak 30 tim, tahun 2018 total yang mendaftar sebanyak 130 tim, tahun 2019 total yang mendaftar sebanyak 69 tim dan tahun 2020 total yang mendaftar sebanyak 99 tim. Perubahan 
tersebut dikarenakan jumlah kuota yang dibatasi berdasarkan klaster perguruan tinggi bidang PKM yang telah ditentukan oleh Belmawa.

Proses bisnis PKM dimulai dari pendaftaran mahasiswa sebagai peserta dalam satu tim sebanyak 3-5 orang, kemudian peserta melakukan penyusunan proposal bersama dosen pembimbing, setelah itu proposal dikumpulkan dan dilakukan proses seleksi oleh tim reviewer, bagi peserta yang lolos seleksi akan diminta untuk melakukan perbaikan dan dialihkan ke tingkat Institusi untuk dibuatkan akun dan submit ke Belmawa. Namun proses yang dijalankan selama ini dapat dikatakan kurang efektif, narasumber mengatakan bahwa proses seleksi memakan waktu dikarenakan pengumpulan proposal masih berupa hard copy dan mengakibatkan adanya penumpukan berkas, di sisi lain berkas dan data terkait juga tidak mudah ditemukan jika sewaktu-waktu ada keadaan yang mengharuskan pihak pengelola mencari dalam waktu singkat.

Berdasarkan permasalahan tesebut, adanya penelitin ini dilakukan untuk merancang sebuah sistem informasi yang terkomputerisasi dengan melakukan observasi, wawancara dan studi pustaka, didukung dengan metode pengembangan sistem Extreme Programming (XP). Metode XP dipilih karena dapat memberikan sebuah fleksibelitas kepada user dengan melibatkan user secara langsung dan memberikan kesempatan kepada klien untuk menambahkan atau merubah proses bisnis aplikasi selama pembangunan aplikasi berjalan[4].

Adapun beberapa penelitian terdahulu dalam berbagai bidang yang menggunakan metode serupa. Penelitian bidang pemerintahan, menghasilkan sistem berbasis desktop pengelolaan surat keterangan kependudukan guna meningkatkan layanan administrasi[5]. Penelitian bidang kesehatan, menghasilkan sistem berbasis android dan website sebagai media konsultasi tanya apoteker terkait edukasi dan informasi obat-obatan[6]. Berdasarkan penelitian yang dikemukakan metode XP mampu diterapkan untuk berbagai pengembangan sistem.

\section{Metodologi PENELITIAN}

Penelitian ini menerapkan metode pengembangan sistem Extreme Programming (XP), dimana merupakan sebuah proses rekayasa perangkat lunak dengan pendekatan berorientasi objek dan tim dalam bentuk skala kecil sampai medium. Model ini melakukan pendekatan secara sistematis dan urut mulai dari level planning yaitu tahap awal pendefinisian kebutuhan fungsional dan non fungsional sistem, design yaitu tahap perancangan yang diterjemahkan dalam sebuah uml, coding yaitu tahap pengkodean perangkat lunak dan testing yang merupakan tahap akhir pengujian sistem yang dilakukan secara berkelanjutan sesuai dengan kebutuhan user[7][8]. Adapun 4 tahapan tersebut yang terlihat seperti pada gambar 1 berikut.

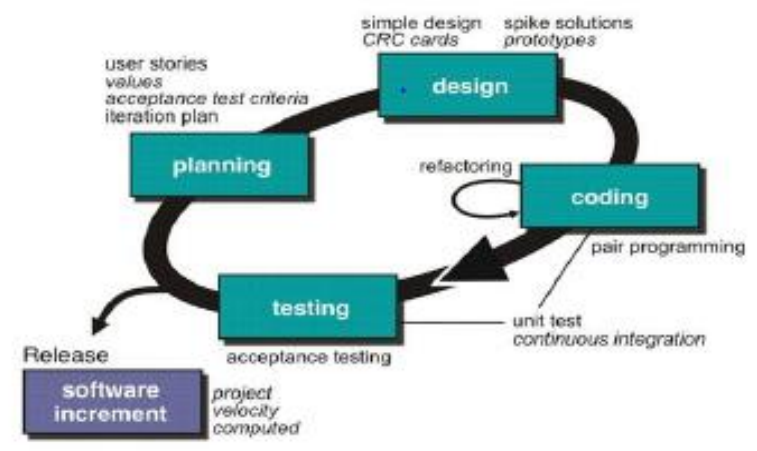

Gambar 1. Konsep Extreme Programming[8].

Tahapan extreme programming

\section{A. Planning}

Tahap awal penelitian dilakukan dengan cara wawancara dengan 2 narasumber selaku pengelola PKM yaitu Ibu Intan Budi Harjayanti dan Bapak Novanda Alim Setya Nugraha, S.S.,M.Hum untuk menganalisa kebutuhan sistem fungsional dan non fungsional sistem yang akan dibuat.

\section{B. Design}

Tahap perancangan diterjemahkan kedalam bahasa UML berupa usecase diagram dan class diagram. Usecase diagram dapat dilihat pada gambar 2 berikut.

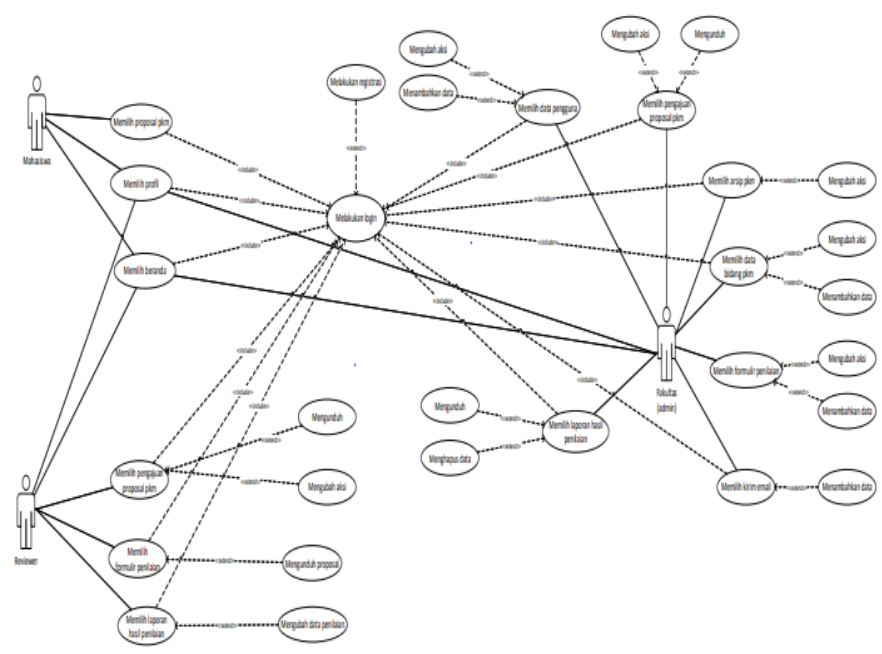

Gambar 2. Usecase Diagram

Gambar 2 menunjukkan bahwa sistem terdiri dari 3 aktor yaitu mahasiswa, reviewer, dan admin. Aktor mahasiswa dapat menampilkan beranda, profil dan mengakses pengajuan proposal pkm. Aktor reviewer dapat menampilkan beranda, profil dan mengakses kelola data penilaian. Aktor admin dapat menampilkan beranda, profil, mengakses pengajuan proposal pkm dan mengelola data. Adapun gambar 3 terkait class diagram berikut. 


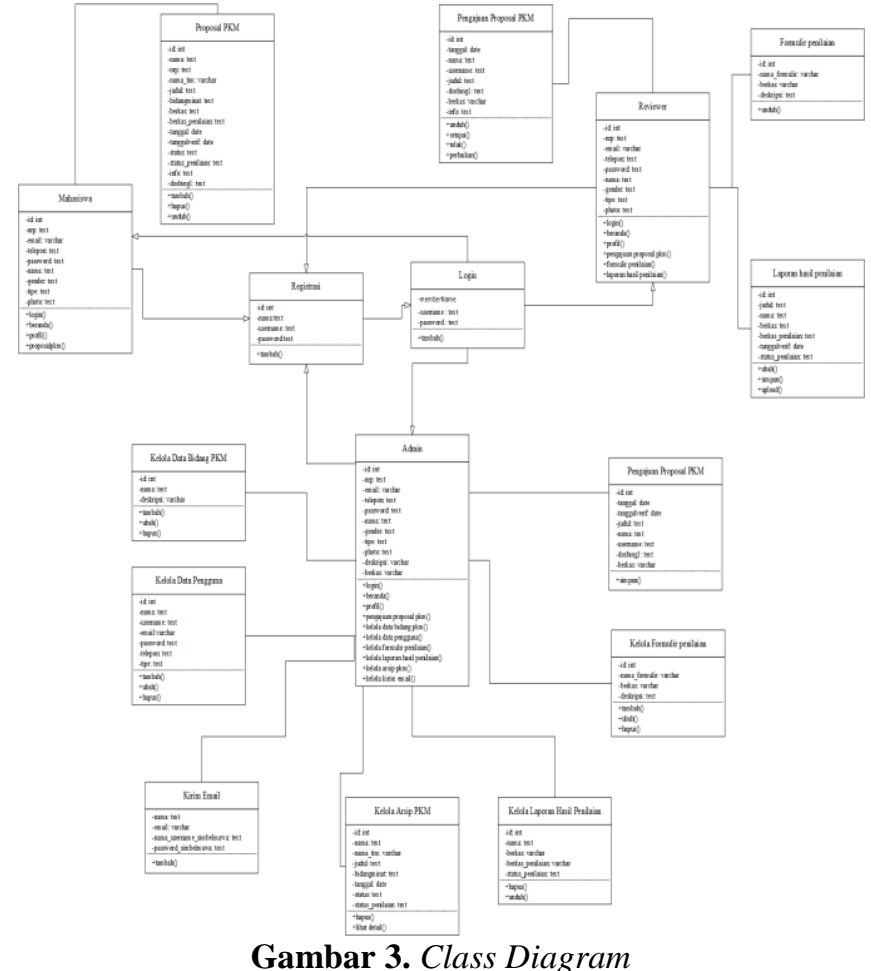

Gambar 3. Class Diagram

Gambar 3 menunjukan function yang memuat banyaknya data dengan tipe data yang berbeda, dimana setiap class saling terhubung dengan class registrasi sebelum user melakukan aksi pada class login. Class mahasiswa terhubung dengan class proposal pkm, class reviewer terhubung dengan class pengajuan proposal pkm, class formulir penilaian dan class laporan hasil penilaian, sedangkan class admin terhubung dengan class pengajuan proposal dan class kelola data.

\section{Coding}

Tahap pengkodean perangkat lunak sesuai dengan perancangan yang telah dibuat sebelumnya dengan menggunakan bahasa pemrograman PHP yang bersifat open source.

\section{Testing}

Tahap pengujian sistem menggunakan blackbox testing guna menguji detail sistem terkait tampilan, fungsionalitas dan kesesuaian alur fungsi dengan bisnis proses dari kebutuhan pengguna dengan berfokus pada output bukan input[9][10].

\section{HASIL DAN PEMBAHASAN}

Hasil penelitian dari setiap tahapan yang ada pada metode Extreme Programming (XP) dalam pengembangan sistem akan dijabarkan sebagai berikut

\section{A. Planning}

Adapun kebutuhan fungsional terkait sstem yang akan dijabarkan pada table 1 berikut
Table 1 Kebutuhan fungsional

\begin{tabular}{c|l}
\hline Judul & \multicolumn{1}{|c}{ Deskripsi } \\
\hline Login & $\begin{array}{l}\text { User mengakses menu dengan memasukan } \\
\text { username dan password }\end{array}$ \\
\hline Registrasi & $\begin{array}{l}\text { User melakukan daftar diri berupa nama } \\
\text { lengkap, username, password }\end{array}$ \\
\hline Beranda & $\begin{array}{l}\text { Tampilan interface berupa informasi } \\
\text { umum terkait pkm }\end{array}$ \\
\hline Profil & $\begin{array}{l}\text { Tampilan interface berupa informasi data } \\
\text { diri yang dapat diubah dan ditambahkan }\end{array}$ \\
\hline $\begin{array}{c}\text { Proposal pkm } \\
\text { Pengajuan } \\
\text { proposal pkm }\end{array}$ & $\begin{array}{l}\text { Mahasiswa memiliki hak akses untuk } \\
\text { mengajukan proposal dan mengisi data } \\
\text { menyetujui proses seleksi penilaian untuk }\end{array}$ \\
\hline $\begin{array}{c}\text { Formulir } \\
\text { penilaian }\end{array}$ & $\begin{array}{l}\text { Reviewer memiliki hak akses untuk } \\
\text { mengunduh format penilaian skema pkm }\end{array}$ \\
\hline $\begin{array}{c}\text { Laporan hasil } \\
\text { penilaian }\end{array}$ & $\begin{array}{l}\text { Reviewer memiliki hak akses untuk } \\
\text { mengupload hasil penilaian }\end{array}$ \\
\hline $\begin{array}{c}\text { Pengajuan } \\
\text { proposal pkm }\end{array}$ & $\begin{array}{l}\text { Admin memiliki hak akses mengelola } \\
\text { ajuan untuk disimpan pada arsip pkm }\end{array}$ \\
\hline $\begin{array}{c}\text { Data bidang } \\
\text { pkm }\end{array}$ & $\begin{array}{l}\text { Admin memiliki hak akses untuk } \\
\text { mengelola informasi data bidang pkm }\end{array}$ \\
\hline $\begin{array}{c}\text { Data } \\
\text { pengguna }\end{array}$ & $\begin{array}{l}\text { Admin memiliki hak akses untuk } \\
\text { mengelola data pengguna }\end{array}$ \\
\hline $\begin{array}{c}\text { Formular } \\
\text { penilaian }\end{array}$ & $\begin{array}{l}\text { Admin dapat melakukan aksi ubah dan } \\
\text { hapus data terkait formular penilaian }\end{array}$ \\
\hline paporan hasil & $\begin{array}{l}\text { Admin data melakukan aksi unduh dan } \\
\text { hapus data laporan hasil penilaian }\end{array}$ \\
\hline Arsip pkm & $\begin{array}{l}\text { Admin dapat melakukan aksi unduh dan } \\
\text { lihat detail arisp pkm yang disimpan }\end{array}$ \\
\hline $\begin{array}{l}\text { Admin memiliki hak akses untuk } \\
\text { menindaklanjuti informasi terkait hasil } \\
\text { seleksi proposal }\end{array}$ \\
\hline Senail
\end{tabular}

Selain itu ada pula kebutuhan non fungsional sistem yaitu:

1) Tehnical requirement

Komponen software berupa penggunaan Bahasa PHP 7 dan windows 10 dan komponen hardwre berupa PC/Komputer dengan standar minimal Core i3, Core i5 dan ram minimal $2 \mathrm{~Gb}$ serta terdapat ssd.

2) Performance requirement

Sistem hanya diakses secara online, apabila koneksi lambat maka response time akan melambat.

3) Usability requirement Tampilan interface berwarna putih ungu dengan tampilan layout berbentuk vertical.

4) Reability requirement

Kecepatan dan kenyamanan akses sistem tergantung banyaknya user yang mengakses secara bersamaan, sistem akan memunculkan reaksi not access jika terdapat trouble.

5) Security requirement

Sistem dilengkapi username dan password yang hanya dimiliki oleh pihak tertentu karena ruang lingkup sistem untuk internal kampus. 


\section{B. Design}

Tahap perancangan dijabarkan dalam bentuk interface, berikut adalah beberapa contoh tampilan yang sudah dibuat.

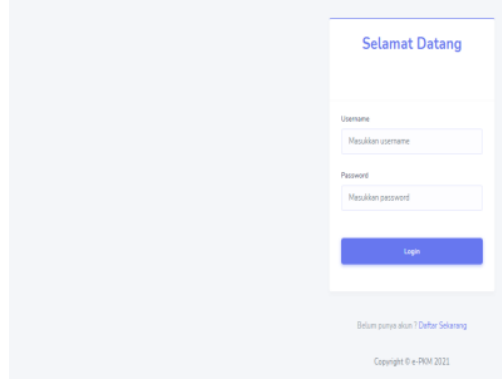

Gambar 4. Tampilan Interface Login

Gambar 4 menampilkan interface login yang berisi username, password untuk user melakukan akses sistem.

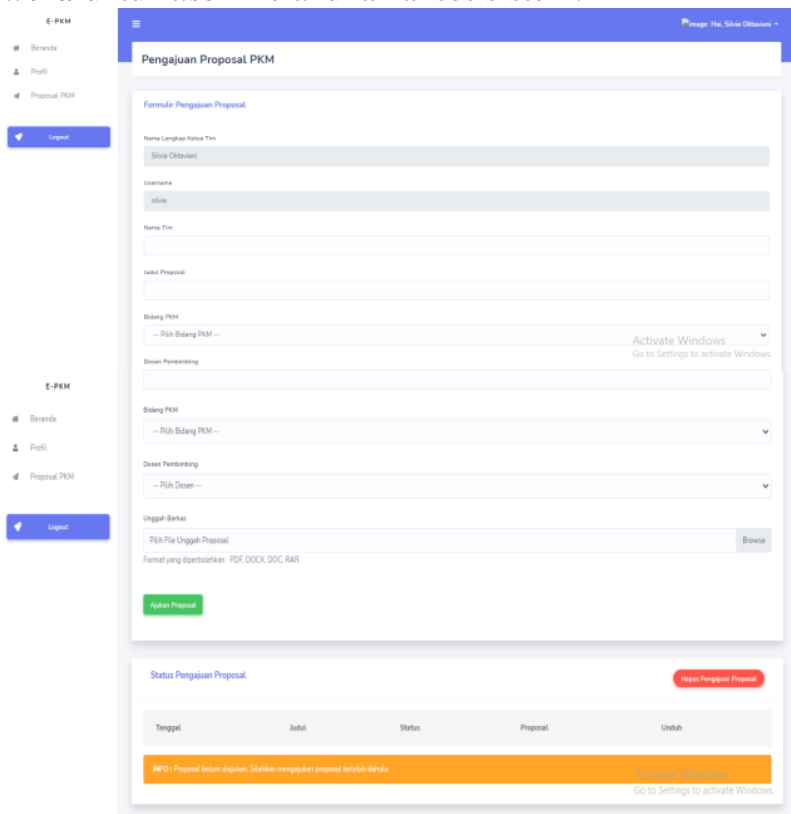

Gambar 5. Tampilan Interface Proposal PKM Mahasiswa Gambar 5 menampilkan interface proposal pkm yang tersedia untuk mahasiswa dalam melakukan pengajuan proposal.

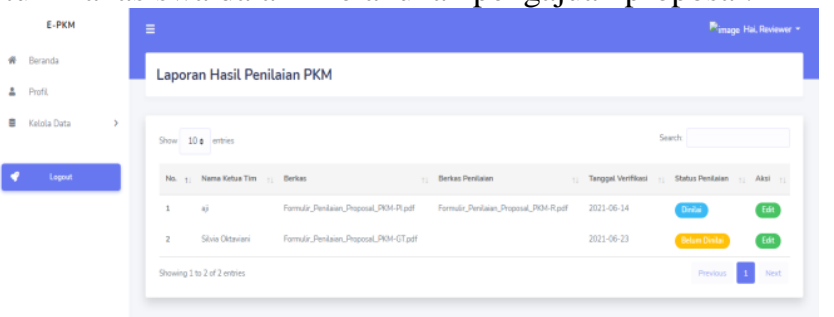

Gambar 6. Tampilan Interface Laporan Hasil Penilaian Gambar 6 menampilkan interface laporan hasil penilaian dari aktor reviewer untuk melakukan aksi unggah hasil penilaian.

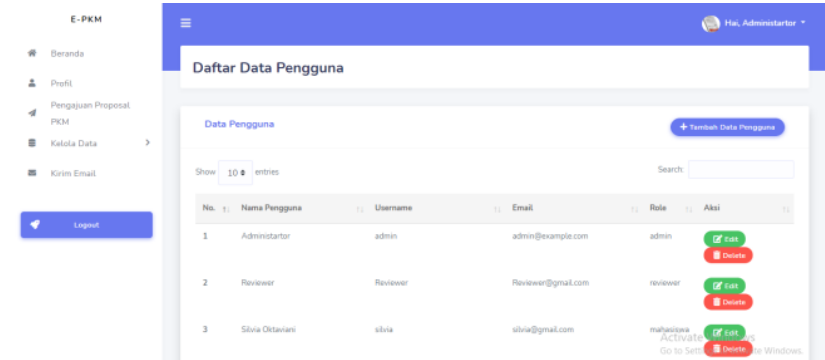

Gambar 7. Tampilan Interface Kelola Data Pengguna Gambar 7 menampilkan interface data pengguna yang hanya bisa dikelola oleh admin dalam menambahkan, mengubah dan menghapus data terkait.

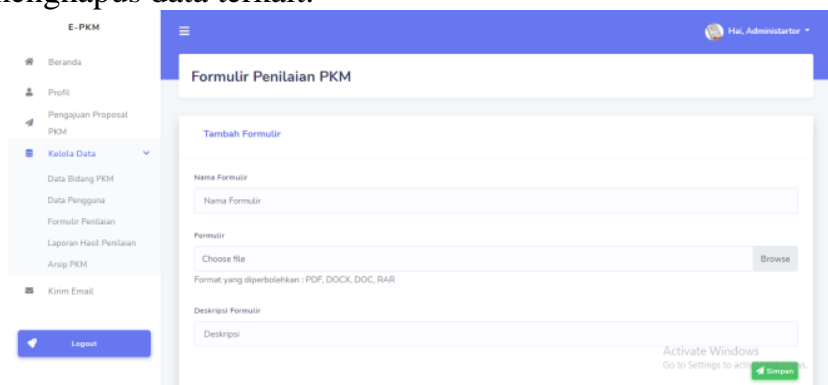

Gambar 8. Tampilan Interface Kelola Formulir Penilaian Gambar 8 menampilkan interface formulir penilaian yang hanya dapat dikelola oleh admin selaku pengelola.

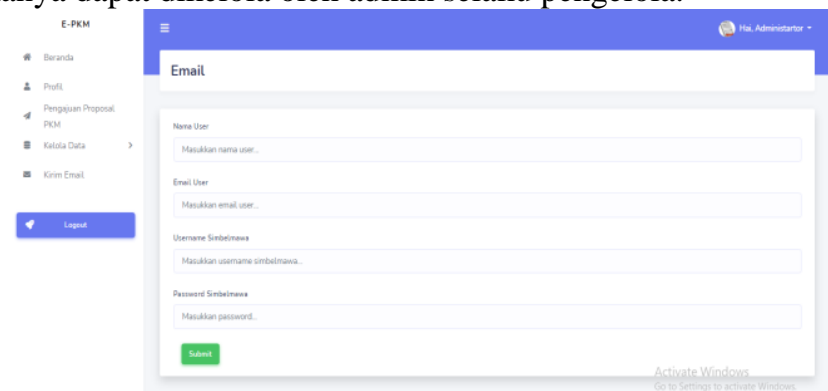

Gambar 9. Tampilan Interface Kirim Email

Gambar 9 menampilkan interface kirim email yang dikelola admin untuk menindaklanjuti hasil seleksi yang lolos dan mendapatkan akun Belmawa.

\section{Coding}

Tahap coding menjabarkan source code sistem dengan menampilkan point utama dari sistem terkait controller, models dan view dengan beberapa source code berikut

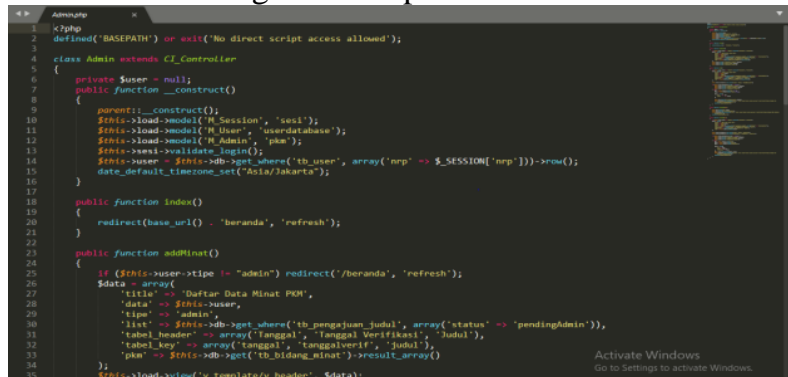

Gambar 10. Source code controller 

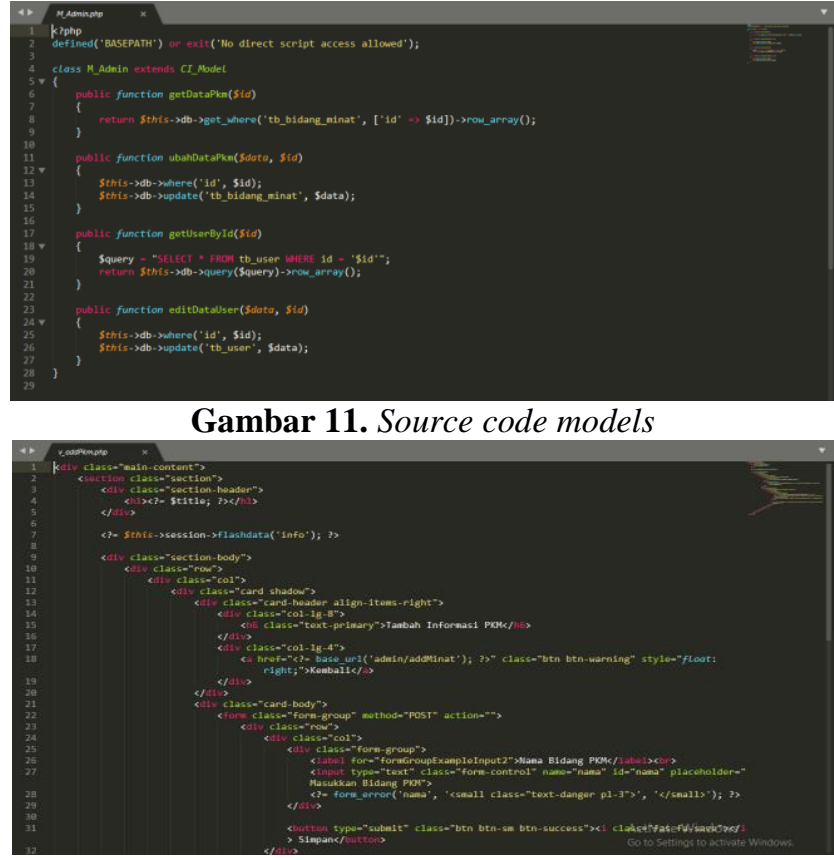

Gambar 12. Source code view

\section{Testing}

Tahap pengujian sistem dilakukan menggunakan blackbox testing kepada 17 pengguna yang terdiri dari 1 admin, 1 reviewer dan 15 mahasiswa. Hasil pengujian dapat dilihat pada tabel 2 berikut.

Tabel 2. Blackbox Testing

\begin{tabular}{|c|c|c|}
\hline Nama & Deskripsi & Hasil \\
\hline Login & Menampilkan halaman awal & Sesuai \\
\hline Registrasi & $\begin{array}{l}\text { Menampilkan dan melakukan } \\
\text { submit data diri }\end{array}$ & Sesuai \\
\hline Beranda & $\begin{array}{l}\text { Menampilkan } \\
\text { beranda }\end{array}$ & Sesuai \\
\hline Profil & $\begin{array}{l}\text { Menampilkan halaman, } \\
\text { mengubah, menyimpan dan } \\
\text { mengunggah data diri }\end{array}$ & Sesuai \\
\hline Proposal pkm & $\begin{array}{l}\text { Menampilkan halaman, } \\
\text { mengajukan, menghapus dan } \\
\text { mengunduh ajuan proposal }\end{array}$ & Sesuai \\
\hline \multirow{2}{*}{$\begin{array}{l}\text { Pengajuan } \\
\text { proposal pkm }\end{array}$} & $\begin{array}{l}\text { Reviewer dapat menampilkan } \\
\text { halaman, mengunduh dan } \\
\text { mengubah }\end{array}$ & Sesuai \\
\hline & $\begin{array}{l}\text { Admin dapat menampilkan, } \\
\text { mengunduh dan menyimpan } \\
\text { data }\end{array}$ & Sesuai \\
\hline \multirow[b]{2}{*}{$\begin{array}{l}\text { Formulir } \\
\text { pemilaian }\end{array}$} & $\begin{array}{l}\text { Reviewer dapat menampilkan } \\
\text { dan mengunduh }\end{array}$ & Sesuai \\
\hline & $\begin{array}{l}\text { Admin dapat menampilkan, } \\
\text { menambahkan, mengubah dan } \\
\text { menghapus data }\end{array}$ & Sesuai \\
\hline $\begin{array}{l}\text { Laporan hasil } \\
\text { penilaian }\end{array}$ & $\begin{array}{l}\text { Reviewer dapat menampilkan, } \\
\text { mengubah dan mengunggah }\end{array}$ & Sesuai \\
\hline
\end{tabular}

\begin{tabular}{c|l|c}
\hline & $\begin{array}{l}\text { Admin dapat menampilkan, } \\
\text { mengunduh dan menghapus } \\
\text { data }\end{array}$ & Sesuai \\
\hline $\begin{array}{c}\text { Data bidang } \\
\text { PKM }\end{array}$ & $\begin{array}{l}\text { Admin dapat menampilkan, } \\
\text { menambahkan, mengubah dan } \\
\text { menghapus data }\end{array}$ & Sesuai \\
\hline $\begin{array}{c}\text { Data } \\
\text { pengguna }\end{array}$ & $\begin{array}{l}\text { Admin dapat menampilkan, } \\
\text { menambahkan, mengubah dan } \\
\text { menghapus data }\end{array}$ & Sesuai \\
\hline Arsip pkm & $\begin{array}{l}\text { Admin dapat menampilkan } \\
\text { dan mengubah aksi }\end{array}$ & Sesuai \\
\hline Kirim email & $\begin{array}{l}\text { Admin dapat menampilkan } \\
\text { dan melakukan submit }\end{array}$ & Sesuai \\
\hline
\end{tabular}

\section{KESIMPULAN}

Penerapan metode Extreme Programming dalam pengembangan sistem dapat dilakukan secara cepat dengan jumlah anggota tim yang minimal terdiri dari beberapa peran antara lain programmer, penguji, orang yang mengerti bisnis, analis, manajer, dan lain-lain. Sistem yang dibuat diharapkan dapat membantu pengelolaan proses bisnis PKM yang digunakan oleh admin, mahasiswa dan reviewer. Hasil pengujian menggunakan blackbox testing menghasilkan hasil yang valid/sesuai.

\section{UCAPAN TERIMA KASIH}

Rasa syukur dan terima kasih ditujukkan kepada Kemahasiswaan Insitut Teknologi Telkom Purwokerto sebagai objek penelitian, dosen pembimbing yang dengan bijaksana memberikan bimbingan saran, kritik dan kontribusi dalam menyelesaikan penelitian ini, dukungan orang tua dan teman teman yang tidak bisa disebutkan satu persatu serta pihak-pihak terkait penelitian sehingga penelitian ini dapat terselesaikan dengan baik.

\section{REFERENSI}

[1] Erma Tita, "ANALISIS DAN PERANCANGAN SISTEM INFORMASI PERPUSTAKAAN,” J. Sist. Inf., Vol. 8, No. 1, Pp. 966-977, 2016.

[2] P. Program, K. Mahasiswa, And P. Umum, BukuPedoman-PKM-2020. 2020.

[3] Kemendikbud, "Program Kreativitas Mahasiswa Pedoman Umum," Kewirausahaan (PKM-K), Vol. 3, Pp. 89-117, 2021.

[4] D. H. Pertiwi, "Metode Extreme Programming (Xp) Pada Website Sistem Informasi Franchise Lkp Palcomtech," J. Mikrotik, Vol. 8, No. 1, Pp. 86-98, 2018.

[5] L. Rusdiana, "Extreme Programming Untuk Rancang Bangun Aplikasi Pengelolaan Surat Keterangan Kependudukan," Regist. J. Ilm. Teknol. Sist. Inf., Vol. 4, No. 1, P. 49, 2018, Doi: 
10.26594/Register.V4i1.1191.

[6] R. Sistem, P. Aplikasi, S. Sistem, I. Tanya, And A. Berbasis, "JURNAL RESTI," Vol. 1, No. 10, Pp. 210-218, 2021.

[7] D. Krisbiantoro Et Al., “(Naskah Diterima: 1 September 2019, Disetujui: 28 Oktober 2019)," Vol. 4, No. November, Pp. 249-258, 2019.

[8] Supriyatna, "Penerapan Metode Extreme Programming Dalam Perancangan Aplikasi Perhitungan Kuota Sks Mengajar Dosen," J. Khatulistiwa Inform., Vol. 3, No. 1, Pp. 106-113, 2018.

[9] A. R. Yahya, "Blackbox Testing Dengan Tomato," DT. Publication, 2019. [Online]. Available: Https://Medium.Com/Pujanggateknologi/BlackboxTesting-Dengan-Tomato-71d63b2307b4. [Accessed: 30-Jun-2020].

[10] "Perbedaan White Box Testing Dan Black Box Testing," Binus University, 2016. [Online]. Available: Https://Student-

Activity.Binus.Ac.Id/Himsisfo/2016/10/PerbedaanWhite-Box-Testing-Dan-Black-Box-

Testing/\#: :Text=Intinya Whitebox Testing Adalah Pengujian,Kepada Detail Pengecekan Kode Program.\&Text=Black Box Testing \%3A Pengujian Yang,Proses Yang Diingin. [Accessed: 30-Jun-2020]. 